\title{
Interactive Effect of Behavioral and Demographic Variables on Individual Investors' Search Behavior
}

\author{
Smita Pandey, Narendra K. Sharma, and Ashok K. Mittal
}

\begin{abstract}
This study explores the information search behavior of individual investors for financial products and services. It applies process tracing techniques and uses an electronic information display board as a tool to understand how information search behavior varies across age, gender, risk aversion attitude, and financial knowledge levels of individual investors. It explores how the interactions between the behavioral and demographic variables affect an individual's information search behavior for equity shares. The results reveal that risk aversion attitude and financial knowledge level combinations differentially affect information search behavior for investors of different age and gender.
\end{abstract}

Index Terms-Depth of search, financial knowledge, financial product, information display board, risk aversion attitude.

\section{INTRODUCTION}

The investigation of the relationship between investment decisions and investors' socioeconomic and demographic characteristics has received considerable attention in academic literature. Demographic characteristics, such as age, life cycle stage, gender, marital status, occupation, income, education, and lifestyle are said to influence any buying decision [1], [2], be it purchase of consumer durables or financial products. They are said to affect various states including interests, tastes, purchasing ability, political preferences, and investment behavior [1]. Investment in financial products is an indispensible part of every household. People save and invest in financial products for various reasons. These reasons include planning for future, to provide safeguard against unforeseen expenditures and income fluctuations in future, and to earn some quick money. The nature of financial product, however, makes investment in such products a complex activity.

Financial products have been described as intangible products as they lack physical dimension [3]. The value of the right of ownership on future benefit is also invisible [4].The intangibility feature of financial products makes investing in such products a complex process and poses difficulties for the investors in evaluation of the attributes as well as in seeking the right information for informed decision making [5], [6].Intangibility of financial products and services increases the uncertainty in the mind of

Manuscript received January 28, 2013; revised March 9, 2013.

Smita Pandey is a Doctoral Student of Department of Industrial and Management Engineering in the Indian Institute of Technology, Kanpur (email: pandeys@iitk.ac.in)

Narendra K. Sharma and Ashok K. Mittal are with Department of Industrial and Management Engineering, IIT Kanpur (e-mail: nksharma@iitk.ac.in,mittal@iitk.ac.in) consumers when they consider buying such products [7]. Risk, thus becomes an inherent feature of financial products. Investment decisions in financial products, therefore, involve a tradeoff between risk and return. It has been well discussed in the literature that the decision making behavior of an individual in a financial product purchase situation is affected by the attitude towards risk as well as the way in which the investment risk is subjectively perceived by the individual [8], [9]. Financial knowledge about market structures, financial products, regulations, economic concepts affecting investment decisions, and government policies etc also becomes unavoidable in case of financial product purchase decisions [10]. Financial knowledge, therefore, plays a vital role in affecting the purchase decision.

The role of information is very significant and vital in decision making for financial products. For financial product decision making, information plays a significant role. This is primarily because financial products are low on search qualities and high on experience and credence quality [11]. Also, investors perceive higher risk in buying financial products and services, which is reduced with greater use of decision relevant information [12]. Investments in financial products require investors to gather, process, and evaluate data on various dimensions that are based on market movements. Consumer information search for financial decisions, however, has not received much attention. There is very little theoretical work on how consumers buy services [13]. Research in this area would be helpful for financial services marketers as it would help them understand how consumers search for information and how they make investment decisions [14].

Few studies in the literature on finance have focused on products like life insurance, banks, and mutual funds [15] [16]. Very little is known about the information processing behavior of stock market investors [17]-[4]. The present study addresses the information search behavior of individual investors possessing certain demographic and behavioral characteristics in case of equity share purchase situation.

The rest of the article is structured as follows: Section II describes the objective of the paper. Section III explains the research method adopted, Section IV explains the results of data analysis. Section $\mathrm{V}$ discusses the findings and concludes the study. Finally, Section VI highlights contribution of the study and indicates the scope for future research.

\section{OBJECTIVE OF THE STUDY}

Voluminous literature exists in the area where 
information search for physical products is shown to be related to most of the demographic characteristics such as age, income, education, gender, marital status, employment type, and family size [18], [19]. Age and gender are the most commonly discussed demographic variables with respect to information search. Other variables that have gained significant attention with respect to information search are the risk attitude and knowledge levels of individual investors. The study by [4] is the pioneer in the field of investors' information search for financial products where information search behavior of common stock purchase was assessed by investors with respect to their demographic characteristics, subjective knowledge, and risk levels. The effect of these variables on information search in the case of financial products and services have been studied in isolation.

This paper provides a different perspective to individual information search behavior based on the interaction between demographics, risk attitude, and financial knowledge of individual investors. Risk aversion attitude and financial knowledge of investors are the two behavioral variables describing an individual's financial behavior in the present study, while age and gender are the variables that describe the demographic characteristics. The main objective of the present study is to explore and understand how available information about "equity shares" is acquired and processed by individual investors of different demographic characteristics having different risk aversion attitude and financial knowledge levels. Process tracing technique of information search is used to study the cognitive processes leading up to a decision.

\section{A. Proposed Hypothesis}

Extant surveys reveal that individuals' subjective knowledge about financial products and services play an important role in shaping their risk preferences [20]-[22]. Investors' risk attitude and knowledge levels can also be affected by their demographic characteristics [23], [24]. Together, the combination of risk attitude and financial knowledge at a particular point in time can alter an individual's investment behavior. The study thus investigates the interactive effect of risk aversion attitude (RAA) and financial knowledge (F_Kn) on depth of search for investors with different demographic characteristics. It thus proposes the following hypothesis:

H1a: Risk aversion attitude and financial knowledge interact significantly with each other across young, middleaged, and old investors to affect depth of information search.

H1b: Risk aversion attitude and financial knowledge interact significantly with each other across male and female investors to affect depth of information search.

\section{RESEARCH METHOD}

This section describes the dependent and the independent variables, measurement mechanism to capture information search dimension, the experiment, and participants of the study.

\section{A. Variables of the Study}

The independent variables of the study are the two demographic variables, namely, age and gender and the two behavioral variables, namely, risk aversion attitude (RAA) and financial Knowledge (F_Kn). On the basis of age, the participants for the study were categorized into three age groups-Young (Y): 20-35 years; middle aged (Mi): 36-50 years; and as Old $(\mathrm{O})$ : 51-65 years. Based on gender, they were categorized as male $(\mathrm{M})$ and female $(\mathrm{F})$.

Risk aversion attitude (RAA) of individual investors was measured on a 5-point scale containing 10 items. The scale measured on two dimensions of RAA, namely, speculative risk (SR) and risk control (RC). Speculative risk described an individual's risk taking tendency and highlighted the gambling behavior of individuals. Risk control, on the other hand, reflected the risk avoiding tendency of the individuals and constantly reminded them that by accepting a higher level of risk, the chances of future losses might increase. Additive procedure was used to compute the risk aversion score of an individual on this scale [25] according to the following equation:

$$
\text { Risk aversion score }(\mathrm{RAS})=\sum \mathrm{RC}-\sum \mathrm{SR}
$$

Based on RAS, the participants were classified into two risk categories: Risk Seeker (RS; negative RAS) and Risk Controller (RC; positive RAS).

Financial knowledge of the participants was measured using a financial knowledge assessment questionnaire (referred as "knowledge test"). The questions of the knowledge test were adapted partially from [26] and partially from [27]. The test broadly measured respondents' financial knowledge (F_Kn) about financial products on following four dimensions: (i) meaning and types of financial products, (ii) functions of the share market, (iii) return and riskiness of financial products, and (iv) regulations in share market. The financial knowledge test contained 20 multiple choice questions with four options in all the questions. The options comprised one correct answer and two wrong answers to the question and one "Don't Know". Based on financial knowledge test scores, participants were classified as high knowledge (H_Kn) investors and low knowledge (L_Kn) investors.

Information search behavior was the dependent variable of the study and was measured in terms of depth of information search [28]. It was defined as the extent (quantity) of information acquired during the experiment. Information on financial product was presented to the participants by using an "Electronic Information Display Board" (EIDB).The Electronic Information Display Board (EIDB) was programmed in MySQL to provide a simulated information search environment. Information was provided on 22 equity share attributes of 12 companies in a matrix (row*column) format. The rows of the matrix contained information about 22 equity share attributes of the 12 companies and columns contained details of 12 companies. All information provided was real and the company name was not disclosed to avoid bias.

Information appeared when a row or column was clicked. A cell in the IDB was designated as $\mathrm{C}_{i} \mathrm{~A}_{j}$ where, $\mathrm{C}_{i}(i=1$ to 12 companies) and $\mathrm{A}_{j}(j=1$ to 22 attributes). All clicks were saved at the back end to make a database for individual participants to study their information processing and 
acquisition pattern. The database was then used to measure depth of search of each participant [29].

Quantitatively, depth of search (DS) was measured on EIDB as the total number of clicks made on EIDB by each participant. Depth of Search (DS) of the $\mathrm{m}^{\text {th }}$ participant was thus expressed as follows

$$
(D S)_{m}=\left[\sum_{i=1}^{12} \sum_{j=1}^{22} C_{i} A_{j}+\sum_{j=1}^{22} \sum_{i=1}^{12} A_{j} C_{i}\right]_{m}
$$

where $\mathrm{C}_{i} \mathrm{~A}_{j}=$ information searched for company $i$ for attribute $j$ where, $i$ ranges from 1-12 and $j$ ranges from 1-22

$\mathrm{A}_{j} \mathrm{C}_{i}=$ information searched for attribute $j$ for company $i$ where, $j$ ranges from 1-22 and $i$ ranges from 1-12

Total DS during the whole experiment was measured as

$$
(D S)_{\text {Total }}=\sum_{m=1}^{43}(D S)_{m}
$$

\section{B. Research Design}

To investigate the interactive effect of behavioral variables (RAA and F_Kn) on depth of search for investors of different age and gender, the experiment involved two between-subjects ANOVA designs. The designs are shown as below:

\section{ANOVA Design 1}

$3($ Age: Y, Mi, O) $\times 2($ RAA: RS, RC) $\times 2($ F_Kn: H_Kn, L_Kn) ANOVA

ANOVA Design 2

2 (Gender: M, F) $\times 2$ (RAA: RS, RC) $\times 2$ (F_Kn: H_Kn, L_Kn) ANOVA

In the above mentioned ANOVA designs, the independent variable, age, comprised three levels, young $(\mathrm{Y})$, middle-aged $(\mathrm{Mi})$, and old $(\mathrm{O})$; gender comprised two levels, male $(\mathrm{M})$ and female $(\mathrm{F})$; risk aversion attitude (RAA) comprised two levels, risk seekers (RS) and risk controllers (RC); and financial knowledge (F_Kn) comprised two levels, high knowledge (H_Kn) individuals and low knowledge ( $\left.\mathrm{L} \_\mathrm{Kn}\right)$ individuals. The dependent variable was depth of information search.

\section{The Experiment}

The experiment repeated here is a part of a larger study and describes only a part of whole data as analyzed below. It involved interviewing 51 individual investors personally. They were asked about their demographic details. Later, risk aversion attitude (RAA) and financial knowledge (F_Kn) questionnaires were filled up by them. This provided the researcher the risk attitude and financial knowledge levels of the participants. The participants were then explained the purpose of the experiment and how the EIDB would work and provided all the relevant information.

The interview began by asking general questions about the investing behavior of the participants. Later, the participants were presented with the scenario of selecting one company's share out of the 12 available options by seeking relevant information across 22 attributes.
Information was provided to the participants as and when they asked for it. Cells in EIDB were clicked to provide them relevant information. All information was real. Forty three individuals participated in the experiment and searched for information while eight individuals did not. These investors made financial decisions mainly on advice from friends, relatives, or any trustworthy persons in their society. The data analysis was done on 43 individuals.

\section{RESUlts AND ANALYSIS}

To investigate the main and interaction effects of age, risk aversion attitude and financial knowledge on depth of search, a 3 (Age: young, middle aged, old) $\times 2$ (RAA: risk seeker, risk controller $) \times 2$ (F_Kn: high financial knowledge, low financial knowledge) way between-subjects factorial ANOVA was computed. The main effects of age, risk aversion attitude (RAA), and financial knowledge (F_Kn) on the depth of search (DS) were found to be statistically significant-Age: $F(2,31)=19.30 \quad p<0.01$; RAA: $F(1,31)=12.58 p<0.05$; and F_Kn: $F(1,31)=$ $31.71 p<0.01$.

These results suggested that there were significant differences in depth of search across investors of different age groups, different risk aversion attitude (RAA), and different financial knowledge (F_Kn). There was a significant interaction effect of RAA and F_Kn on depth of search of information for different age groups $-F(1,31)=$ $5.964 p<0.05$. This means that the investors of different risk and financial knowledge combinations for different age groups employ significantly different depth of search. Hypothesis H1a was thus supported.

As significant interactions were found between RAA and F_Kn for depth of search, simple effects analysis was conducted to analyze the effect of risk aversion attitude and financial knowledge at each level of age. Table I shows the result of simple effects analyses for the three age groups. As evident from Table I, interaction of RAA $\times$ F_Kn was significant for young investors and old investors, while it was not significant for middle aged investors.

TABLE I: RESULTS OF SIMPLE EFFECTS ANALYSIS FOR INVESTORS OF DIFFERENT AGE GROUPS

\begin{tabular}{c|l|c|c|c}
\hline Source & \multicolumn{1}{|c|}{ Age group } & df & MS & F \\
\hline \multirow{3}{*}{ RAA*F_Kn } & Young & 1 & 310.805 & $7.089^{*}$ \\
\cline { 2 - 5 } & Middle aged & 1 & 5.8 & 0.095 \\
\cline { 2 - 5 } & Old & 1 & 196.909 & $13.305^{*}$ \\
\hline
\end{tabular}

$\mathrm{N}=43$; *p<.05; RAA = Risk Aversion Attitude; F_Kn = Financial Knowledge

The results presented in Table I indicate that the depth of search was affected by the risk and knowledge profile for young and old investors. The graphical representations of the interaction in Fig. 1 for the three age groups make this observation more clear.

The simple effects were further broken down to explore the effect of RAA for each level of F_Kn and vice-versa for young and old investors by applying simple-simple effect analysis. Table II present the results of simple-simple effects analysis for young and old investors respectively. 
TABLE II: RESULTS OF SIMPLE-SIMPLE EFFECTS ANALYSIS FOR YOUNG INVESTORS WITH DIFFERENT RISK AVERSION ATTITUDE

\begin{tabular}{c|l|c|c|c}
\multicolumn{4}{c}{ ACROSS FINANCIAL KNOWLEDGE LEVELS } \\
\hline \multicolumn{1}{c|}{ RAA } & \multicolumn{1}{|c|}{ F_Kn } & df & MS & F(1,31) \\
\hline \multirow{4}{*}{ Risk Seekers } & $\begin{array}{l}\text { High } \\
\text { Knowledge }\end{array}$ & 1 & 0.25 & 0.005 \\
\cline { 2 - 2 } & $\begin{array}{l}\text { Low } \\
\text { Knowledge }\end{array}$ & & & \\
\hline \multirow{2}{*}{ Risk Controllers } & $\begin{array}{l}\text { High } \\
\text { Knowledge }\end{array}$ & \multirow{2}{*}{1} & 585.21 & $\mathbf{1 3 . 2 7 * *}$ \\
\cline { 2 - 3 } & $\begin{array}{l}\text { Low } \\
\text { Knowledge }\end{array}$ & & \\
\hline
\end{tabular}

$\mathrm{N}=43 ; * \mathrm{p}<.05 ; \mathrm{RAA}=$ Risk Aversion Attitude; F_Kn = Financial Knowledge

The above results suggested that among young risk controllers, high financial knowledge level impels investors to search significantly more information as compared to their low financial knowledge counterparts, while there is no such effect among young risk seekers. Similarly simplesimple effects analyses were applied to explore the effect of RAA for each level of $\mathrm{F} \_\mathrm{Kn}$ and vice-versa for old investors. The result of simple-simple effect analysis for old investors is presented in Table III.

TABLE III: RESULTS OF SIMPLE-SIMPLE EFFECTS ANALYSIS FOR OLD INVESTORS WITH DIFFERENT RISK AVERSION ATTITUDE ACROSS

\begin{tabular}{|c|c|c|c|c|}
\hline \multicolumn{5}{|c|}{ FINANCIAL KNOWLEDGE LEVELS } \\
\hline RAA & F_Kn & df & MS & $\mathbf{F}(\mathbf{1 , 3 1 )}$ \\
\hline \multirow{2}{*}{ Risk Seekers } & $\begin{array}{l}\text { High } \\
\text { Knowledge }\end{array}$ & \multirow{2}{*}{1} & \multirow{2}{*}{120} & \multirow{2}{*}{2.72} \\
\hline & $\begin{array}{l}\text { Low } \\
\text { Knowledge }\end{array}$ & & & \\
\hline \multirow{2}{*}{ Risk Controllers } & $\begin{array}{l}\text { High } \\
\text { Knowledge }\end{array}$ & \multirow{2}{*}{1} & \multirow{2}{*}{841.0} & \multirow{2}{*}{$19.07 * *$} \\
\hline & $\begin{array}{l}\text { Low } \\
\text { Knowledge }\end{array}$ & & & \\
\hline
\end{tabular}

$\mathrm{N}=43 ; * \mathrm{p}<.05 ; \mathrm{RAA}=$ Risk Aversion Attitude; $\mathrm{F} \_\mathrm{Kn}=$ Financial Knowledge
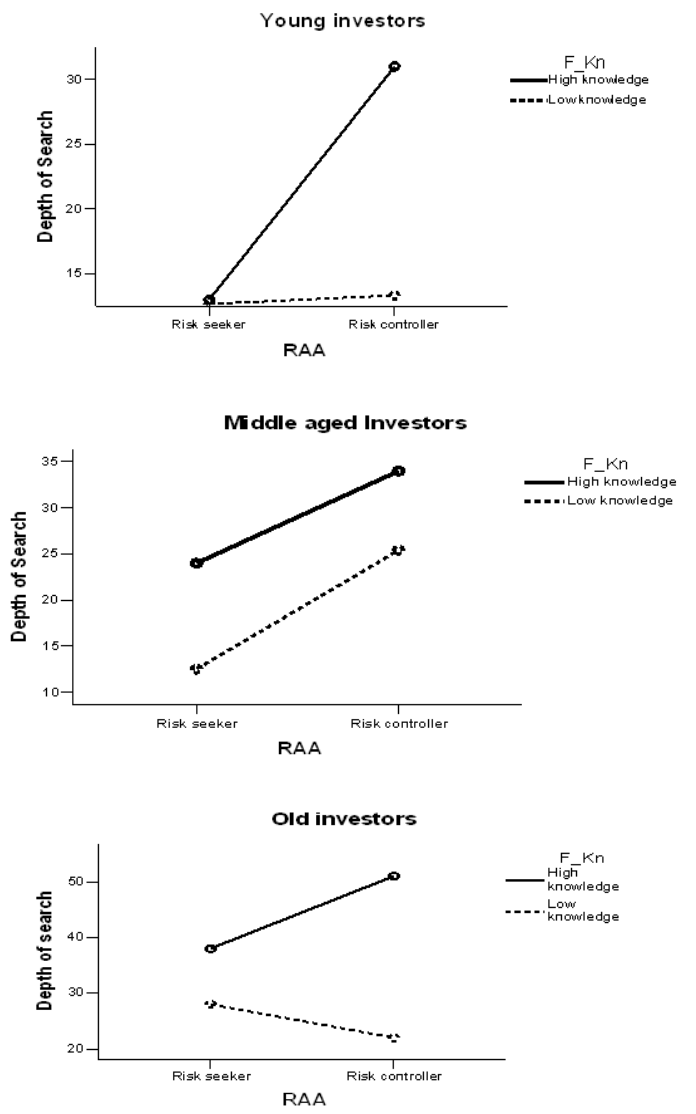

Fig. 1. Interaction between risk aversion attitude and financial knowledge (Young, Middle-aged and Old investors)
The above results suggested that among young risk controllers, high financial knowledge level impels investors to search significantly more information as compared to their low financial knowledge counterparts while there is no such effect among young risk seekers. Similarly, simplesimple effects analyses were applied to explore the effect of RAA for each level of $F_{-}$Kn and vice-versa for old investors. The result of simple-simple effect analysis for old investors is presented in Table IV.

TABLE IV: RESUlTS OF SIMPLE-SIMPLE EFFECTS ANALYSIS FOR OLD INVESTORS WITH DIFFERENT RISK AVERSION ATTITUDE ACROSS

\begin{tabular}{|c|c|c|c|c|}
\hline \multicolumn{5}{|c|}{ FINANCIAL KNOWLEDGE LEVELS } \\
\hline RAA & F_Kn & df & MS & $\mathbf{F}(\mathbf{1 , 3 1 )}$ \\
\hline \multirow{2}{*}{ Risk Seekers } & High Knowledge & \multirow{2}{*}{1} & \multirow{2}{*}{120} & \multirow{2}{*}{2.72} \\
\hline & Low Knowledge & & & \\
\hline \multirow{2}{*}{ Risk Controllers } & High Knowledge & \multirow{2}{*}{1} & \multirow{2}{*}{841.0} & \multirow{2}{*}{$19.07 * *$} \\
\hline & Low Knowledge & & & \\
\hline
\end{tabular}

$\mathrm{N}=43 ;{ }^{*} \mathrm{p}<.05 ; \mathrm{RAA}=$ Risk Aversion Attitude; F_Kn = Financial Knowledge

The results of Table III suggested that among old risk controllers, high financial knowledge level makes investors to search significantly more information as compared to their low financial knowledge counterparts. No such effect was observed for old risk seekers. Further, to investigate the main and interaction effects of gender, risk aversion attitude, and financial knowledge on the depth of search, a 2 (Gender: male, female) $\times 2$ (RAA: risk seeker, risk controller) $\times 2$ (F_Kn: high knowledge, low knowledge) way between-subjects factorial ANOVA was computed. There were significant main effects of gender $(\mathrm{F}(1,35)=$ 9.70, p<0.01), RAA $(\mathrm{F}(1,35)=9.37, \mathrm{p}<0.01)$, and F_Kn $(\mathrm{F}$ $(1,35)=3.85, \mathrm{p}<0.05)$ on depth of search. These results suggested that there were significant differences in depth of search across investors of different genders, different risk aversion attitude (RAA), and different financial knowledge (F_Kn).

There was a significant interaction effect between RAA and F_Kn on depth of search for female investors $(\mathrm{F}(1,35)$ $=4.61 \mathrm{p}<0.05)$. This means that the investors of different RAA and F_Kn combinations had significantly different depth of search across different genders. The hypothesis $\mathrm{H} 1 \mathrm{~b}$ was thus supported.

As significant interactions were found, simple effects analyses were applied to examine the differences in depth of search between male and female investors for combinations of RAA and F_Kn. Table V shows the results of simple effects analysis for investors of different gender.

TABLE V: RESULTS OF SIMPLE EFFECTS ANALYSIS FOR INVESTORS OF

\begin{tabular}{c|l|c|c|c|}
\multicolumn{5}{c}{ DIFFERENT GENDER } \\
\hline Source & \multicolumn{1}{|c|}{ Age group } & df & MS & F \\
\multirow{2}{*}{ RAA*F_Kn } & Male & 1 & 130.80 & 1.3 \\
\cline { 2 - 5 } & Female & 1 & 259.20 & $6.82 *$
\end{tabular}

$\mathrm{N}=43 ; * \mathrm{p}<.05 ;$ RAA $=$ Risk Aversion Attitude; $\mathrm{F}_{-} \mathrm{Kn}=$ Financial Knowledge

Results presented in Table IV indicate that the depth of search was affected by interaction of behavioral variables namely, RAA and F_Kn among female investors only. RAA and F_Kn did not interact significantly to affect the depth of search among male investors. The graphical representation of the interactions between risk aversion attitude and 
financial knowledge for male and female investors is presented in Fig. 2. The graphical representations indicated a non significant (Figure 2 (a)) and a significant (Figure 2 (b)) interaction effect of risk aversion attitude and financial knowledge among male and female investors respectively.

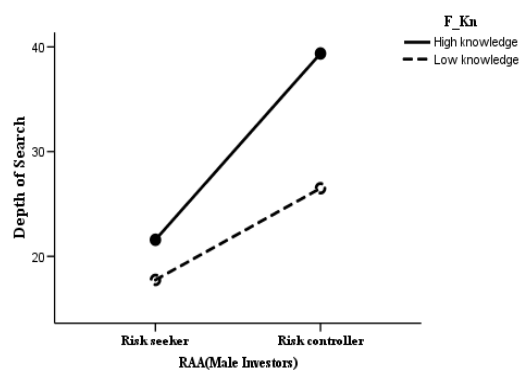

Fig. 2(a). Interaction between Risk Aversion Attitude and Financial Knowledge for Male Investors.

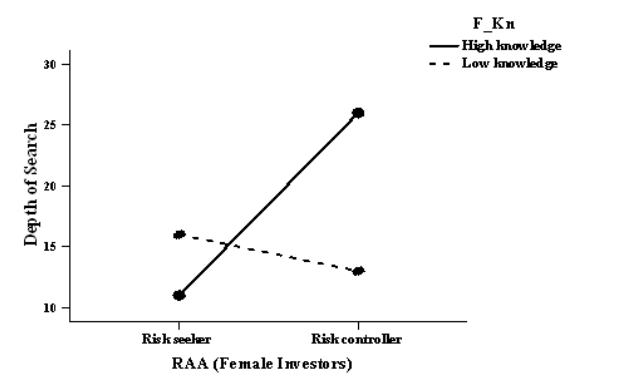

Fig. 2(b). Interaction between Risk Aversion Attitude and Financial Knowledge for Female Investors.

The simple effects were further broken down to explore the effect of RAA for each level of $\mathrm{F}_{-} \mathrm{Kn}$ and vice-versa for female investors by applying simple-simple effect analysis as RAA and F_Kn interact significantly to affect depth of search only among female investors. Table VI summarizes the results of simple-simple effects analysis for female investors. The results suggested that among risk controllers, females with high financial knowledge level searched for significantly more information as compared to their low financial knowledge counterparts. No such effect was observed among female risk seekers.

TABLE VI: RESULTS OF SIMPLE-SIMPLE EFFECTS ANALYSIS FOR FEMALE INVESTORS WITH DIFFERENT RISK AVERSION ATTITUDE ACROSS FINANCIAL KNOWLEDGE LEVELS

\begin{tabular}{|c|c|c|c|c|}
\hline RAA & F_Kn & df & MS & $\mathbf{F}(\mathbf{1 , 3 5 )}$ \\
\hline \multirow{2}{*}{ Risk Seekers } & High Knowledge & \multirow{2}{*}{1} & \multirow{2}{*}{37.5} & \multirow{2}{*}{0.44} \\
\hline & Low Knowledge & & & \\
\hline \multirow{2}{*}{ Risk Controllers } & High Knowledge & \multirow{2}{*}{1} & \multirow{2}{*}{289.71} & \multirow{2}{*}{$3.43^{*}$} \\
\hline & Low Knowledge & & & \\
\hline
\end{tabular}

$\mathrm{N}=43 ;{ }^{*} \mathrm{p}<.05 ;$ RAA $=$ Risk Aversion Attitude; F_Kn $=$ Financial Knowledge

The above results suggested that among risk controllers, females with high financial knowledge level searched for significantly more information as compared to their low financial knowledge counterparts. No such effect was observed among female risk seekers.

\section{DISCUSSION}

Studies in the past have expressed that individuals' demographic characteristics shape up their risk preferences. Also, risk preferences get affected by the level of financial knowledge that one possesses. Added knowledge about financial products and markets can also alter an individual's risk taking capabilities. Studies till date have explored the relationship of specific variables and information search in isolation. The present study attempted to explore the interaction effect of behavioral variables, namely, RAA and F_Kn, across different levels of demographic variables, namely, age, and gender.

There have been studies in the past that have explored the relationship between information search and investors demographic categories individually [30], [31]. The present study puts forth the picture in totality. It asserts that individuals do not represent a particular demographic category only, instead, they are combination of demographics along with risk attitude and financial knowledge. The finding of the present study is therefore unique in its way. The findings of the present study suggest that financial knowledge combined with risk aversion attitude level affects the information search behavior of old and young investors. Similarly, financial knowledge interacts with risk aversion attitude levels to affect the search behavior of female investors. Male investors' search behavior is not affected by their financial knowledge and risk aversion attitude levels. The findings of the study thus offer insights to the literature related to information search. With respect to age, the study revealed that extent of information search, it is the old and the young risk controllers who posses high financial knowledge would indulge into significantly higher depth of search as compared to investors of other sets of demographic and behavioral combinations. With respect to gender, female risk controllers with high financial knowledge would search for significantly more information compared to investors of other sets of demographic and behavioral combinations.

\section{CONTRIBUTION AND SCOPE FOR FUTURE RESEARCH}

The present study contributes to the literature by providing a measure of information search behavior in case of financial products. The search behavior is recorded as a dynamic and ongoing event (by using an EIDB) and not merely as a reporting measure. It captures the information search behavior when the search is actually taking place. Literature so far has relied on questionnaires and reports in which responses are provided once the search is over. Financial knowledge also is a real measure of knowledge about financial products and the financial market. Knowledge in literature so far, has been a self-reported measure. The findings of the present study will be helpful to providers of financial products by giving them a clear and more comprehensive picture about the search behavior of the investors with a risk and financial knowledge profile in combination with their age group and gender. The study can be further expanded to take into account other demographic variables like income, marital status, education, occupation, etc., and how they affect information search behavior. This study captures the depth of search, i.e., how much information is looked for; studies can be further taken up to explore "what" information is looked for by the investors with a certain demographic, risk, and knowledge profile. 


\section{REFERENCES}

[1] P. Kotler and G. Armstrong, Principles of Marketing, Eleventh Edition, Prentice-Hall, 2006.

[2] L. G. Schiffman and L. L. Kanuk, Consumer behavior, 9th Edition, Prentice Hall, 2006.

[3] P. Hill, "Tangibles intangibles and services: a new taxonomy for classification of output," Canadian Journal of Economics, vol. 32, no. 2, pp. 426-446, 1999.

[4] Q. C. Lin and J. Lee, "Consumer information search when making investment decisions," Financial Services Review, vol.13, no. 4, pp. 319-332, 2004.

[5] D. W. Miller and J. E. Foust, "Classifying services by tangibility/intangibility of attributes and benefits," Services Marketing Quarterly, vol. 24, no. 4, pp. 35-55, 2003.

[6] L. W. Turley and R. P. LeBlanc, "An exploratory investigation of consumer decision making in the service sector," The Journal of Services Marketing, vol. 7, no. 4, pp. 11-18, 1993.

[7] V. W. Mitchell and M. Greatorex, "Risk perception and reduction in the purchase of consumer services," The Service Industries Journal, vol. 13 , no. 4, pp. 179-200, 1993.

[8] S. B. Sitkin and A. L. Pablo, "Reconceptualizing the determinants of risk behavior," Academy of Management Review, vol. 17, no. 1, pp. 9-39, 1992.

[9] S. B. Sitkin and L. R. Weingart, "Determinants of risky decisionmaking behavior: A test of the mediating role of risk perceptions and propensity," Academy of Management Journal, vol. 38, no. 6, pp. 1573-1592, 1995.

[10] J. H. Dulehohn, "An investigation of the determinants of investment risk behavior in employer-sponsored retirement plans," Journal of Management, vol. 20, no. 1, pp. 3-26, 2002.

[11] V. A. Zeithaml, 1981, How consumer evaluation processes differ between goods and services, Reprinted in Lovelock, C., Services Marketing, and (2nd ed.), Upper Saddle River, New Jersey: Prentice, 1991.

[12] K. B. Murray, "A test of services marketing theory: Consumer information acquisition activities," Journal of Marketing, vol. 55, pp. $10-25,1991$.

[13] J. F. Devlin, "Consumer evaluation and competitive advantage in retail financial services - A research agenda," European Journal of Marketing, vol. 35, no. 5-6, pp. 639-660, 2000.

[14] S. Mckenhie, "Consumer buying behavior in financial services: An overview," International Journal of Bank Marketing, vol. 19, no. 5, pp. 4-12, 1992.

[15] J. Lee and J. Marlowe, "How Consumers Choose a Financial Institution: Decision Making Criteria and Heuristics," The International Journal of Bank Marketing, vol. 21, no. 2, 2003.

[16] N. Capon, G. J. Fitzsimons, and R. A. Prince, "An individual level analysis of the mutual fund investment decision," Journal of Financial Services Research, vol. 10, no. 1, pp. 59-82, 1996.

[17] M. Morrin, J. Jacoby, G. V. Johar, X. He, A. Kuss, and D. Mazursky, "Taking stock of stockbrokers: Exploring momentum and contrarian investor strategies and profiles," Journal of Consumer Research, vol. 29, no. 2, pp. 188-198, 2002.

[18] S. E. Beatty and S. M. Smith, "External search effort: An investigation across several product categories," Journal of Consumer Research, vol. 14, no. 1, pp. 83-95, 1987.

[19] C. Guo, "A review on consumer external search: Amount and determinants," Journal of Business and Psychology, vol. 15, no. 3, pp. 505-519, 2001.

[20] J. E. Grable and S. H. Joo, "Determinants of risk preference: Implications for family and consumer science professionals," Family Economics and Resource Management Biennial, vol. 2, pp. 19-24, 1997.

[21] J. E. Grable and R. H. Lytton, "Determinants of retirement savings plan participation: A discriminant analysis," Personal Finances and Worker Productivity, vol. 1, no. 1, pp. 184-189, 1997.

[22] J. Sung and S. Hanna, "Factors related to risk tolerance," Financial Counseling and Planning, vol. 7, pp. 11-20, 1996.

[23] A. M. Palsson, "Does the degree of relative risk aversion vary with household characteristics?” Journal of Economic Psychology, vol. 17, pp. 771-787, 1996.

[24] D. P. Brown, "Age clienteles induced by liquidity constraints," International Economic Review, vol. 31, pp. 891-912, 1990.
[25] N. Lampenius and M. J. Zickar, "Development and validation of a model and measure of financial risk-taking," The Journal of Behavioral Finance, vol. 6, no. 3, pp. 129-143, 2005.

[26] D. Evans, J. Holcomb, and W. Chittenden, "The relationship between risk return preference and knowledge in experimental financial markets," The Journal of Behavioral Economics, vol. 18, no. 1, pp. 19-40, 1989

[27] M. V. Rooij, A. Lusardi, and R. Alessie, "Financial literacy and stock market participation," Working paper, Michigan Retirement Research Center, University of Michigan, pp. 2-46, 2007.

[28] J. Jacoby, J. G. Szybillo, and B. J. Schach, "Information acquisition behavior in brand choice situations," Journal of Consumer Research, vol. 3, pp. 209-216, 1977.

[29] J. Jacoby, R. W. Chestnut, and W. A. Fisher, "A behavioral process approach to information acquisition in nondurable purchasing," Journal of Marketing Research, vol. 15, pp. 512-544, 1978.

[30] M. T. Elliott, "An investigation of consumer information search for professional services," Journal of Marketing Management, vol. 4, no. 2, pp. 8-22, 1998.

[31] C. A. Cole and S. K. Balasubramanian, "Age differences in consumers' search for information: Public policy implications," Journal of Consumer Research, vol. 20, no. 1,pp. 157-169, 1993.

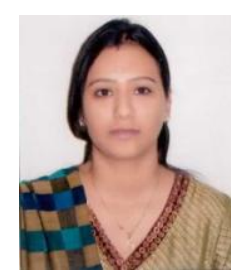

Smita Pandey is a doctoral student of Department of Industrial and Management Engineering in the Indian Institute of Technology, Kanpur. Born at Varanasi in India on 1st of February,1980, she did her Graduation from IP College for Women, Delhi University in the year 2001 and later pursued her Masters in Finance (MFC) from Banaras Hindu University in the year 2003. Her research interests are in the area of behavioral finance and corporate finance.

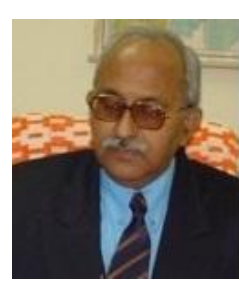

Narendra K. Sharma is a professor in the Department of Industrial and Management Engineering, Indian Institute of Technology Kanpur, India. He did his Masters and PhD in Psychology from Delhi University. His interest areas include consumer behavior, cognitive psychology, engineering psychology, and experimental psychology. He has conducted a number of seminars and workshops and has several articles published in journals and conference proceedings to his credit.

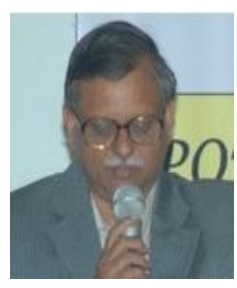

Dr. Ashok Mittal is currently a professor in Industrial and Management Engineering Department at the Indian Institute of Technology Kanpur. He earned his Ph.D. in Operations Research from Case Western Reserve University. His research interests are in Operations Research, Operations Management, and Intellectual Property Rights. $\mathrm{He}$ is past president of Operations Research 